\title{
Effects of Sugars on Glycosidase Secretion in Dictyostelium discoideum
}

\author{
By EDMUND V. CREAN AND EDWARD F. ROSSOMANDO \\ Department of Oral Biology, University of Connecticut Health Center, \\ Farmington, Connecticut 06032, U.S.A.
}

(Received 24 July 1978)

\begin{abstract}
When exponentially growing Dictyostelium discoideum amoebae were harvested from growth medium and suspended in a nutrient-free phosphate buffer, the cells released 20 to $30 \%$ of their total $\beta$ - $N$-acetylglucosaminidase and $\alpha$-mannosidase activities. This release was inhibited by sodium azide but stimulated (to a level of $90 \%$ release) by various saccharides when added to the phosphate buffer at millimolar concentrations. Various salts, amino acids and nucleotides were unable to stimulate the release process. Non-metabolizable sugars were more stimulatory than metabolizable sugars, but no clear distinction related to structure, ability to be transported or ability to be metabolized was found to account directly for the varying effects of the sugars on glycosidase release. The rate and amount of glycosidase release was dependent on the sugar concentration but not on the cell density. The results presented suggest that sugars stimulate a specific release of a variety of lysosomal enzymes and the relationship of this release to $D$. discoideum morphogenesis is discussed.
\end{abstract}

\section{INTRODUCTION}

At the onset of starvation, the independent amoebae of the cellular slime mould Dictyostelium discoideum aggregate into masses of cells which eventually form a sporulating fruiting body composed of two distinct cell types (Loomis, 1975). During morphogenesis the carbohydrate content of the cells is maintained despite large decreases in protein and RNA content (White \& Sussman, 1961), suggesting that the metabolism of glyco-substances is tightly controlled in this organism. In a previous report (Crean \& Rossomando, 1977), we suggested that secreted glycosidases may modify cell surface glyco-substances in $D$. discoideum during the period when the cells become aggregation-competent, and Ashworth \& Quance (1972) have suggested that the secretion of the glycosidases may be of developmental significance. Since Rahmsdorf et al. (1976) have reported that metabolizable sugars can block the acquisition of aggregation competence in $D$. discoideum, as well as many of the biochemical changes which occur early in development, this study was undertaken to examine the effects of sugars on glycosidase secretion during this period. The results presented demonstrate a striking effect of sugars on glycosidase secretion and raise several questions regarding the role of various lysosomal enzymes in $D$. discoideum morphogenesis.

\section{METHODS}

Organisms. An axenic derivative (Ax-3) of the cellular slime mould Dictyostelium discoideum (NC-4, haploid) was used for all experiments. Amoebae were grown in HL-5 medium as previously described (Rossomando et al., 1974).

To initiate development, cells were harvested during the exponential growth phase $\left(1 \times 10^{6}\right.$ to $2 \times 10^{6}$ cells $\mathrm{ml}^{-1}$ ) by centrifugation $(3000 \mathrm{~g}, 5 \mathrm{~min})$, suspended at $1 \times 10^{7}$ to $2 \times 10^{7}$ cells $\mathrm{ml}^{-1}$ in starvation buffer $(17 \mathrm{mM}-$ 
potassium phosphate, $\mathrm{pH} 6 \cdot 1$, containing $2 \mathrm{mM}-\mathrm{MgSO}_{4}$ ) and incubated on a rotary shaker at $22{ }^{\circ} \mathrm{C}$. Under these conditions the cells become aggregation-competent within $12 \mathrm{~h}$.

Secretion studies. For all secretion experiments, the cells were harvested from growth medium, suspended as described above in either starvation buffer alone or starvation buffer containing sugar and incubated on a shaker. At various times $1 \mathrm{ml}$ samples of the cell suspensions were taken and centrifuged at $3000 \mathrm{~g}$ for $5 \mathrm{~min}$. The supernatants were mixed with $0.1 \mathrm{ml} 1 \%$ (v/v) Triton X-100 before assaying for secreted enzyme activities. The cell pellets were vortexed in $1 \mathrm{ml} 1 \%$ Triton X-100. Each of these fractions was stored at $4^{\circ} \mathrm{C}$ until used for enzyme assays.

Enzyme assays. $\beta$ - $N$-Acetylglucosaminidase (EC 3.2.1.30) activity was assayed by a modification of the procedure described by Loomis (1969). Samples were incubated at $30{ }^{\circ} \mathrm{C}$ with $5 \mathrm{~mm}$ - $p$-nitrophenyl- $\beta$ $N$-acetylglucosaminide in $0.05 \mathrm{M}$-acetate buffer $(\mathrm{pH} 5.0)$ in a total volume of $0.1 \mathrm{ml}$. After 5 to $30 \mathrm{~min}$, the reaction was stopped by adding $0.9 \mathrm{ml} 1 \mathrm{M}$-Tris/HCl buffer $(\mathrm{pH} \mathrm{9.0)}$ and the absorbance was measured at $400 \mathrm{~nm}$. Acid phosphatase (EC 3.1.3.2) activity was measured under identical conditions using $5 \mathrm{~mm}$ p-nitrophenyl phosphate as substrate. $\alpha$-Mannosidase (EC 3.2.1.24) activity was measured in the same manner using $5 \mathrm{~mm}$-p-nitrophenyl- $\alpha$-mannoside in acetate buffer (pH 4.0). Cyclic nucleotide phosphodiesterase (EC 3.1.4.17), 5'-nucleotidase (EC 3.1.3.5) and alkaline phosphatase (EC 3.1.3.1) activities were assayed as previously described (Crean \& Rossomando, 1977). For each activity one unit is equivalent to the production of $1 \mu \mathrm{mol}$ product $\mathrm{h}^{-1}$ at $30^{\circ} \mathrm{C}$. Protein was determined by the procedure of Lowry et al. (1951) using crystalline bovine serum albumin as standard.

Sugar uptake. Vegetative cells were suspended at $1.5 \times 10^{2}$ cells ml $^{-1}$ in starvation buffer containing $0.1 \mathrm{M}$ ${ }^{14} \mathrm{C}$-labelled sugar $\left(10 \mathrm{mCi} \mathrm{mol}^{-1}\right)$. At $1 \mathrm{~h}$ intervals, $0.5 \mathrm{ml}$ samples were taken and mixed with $3 \mathrm{ml}$ of ice-cold starvation buffer containing $50 \mathrm{~mm}$-sucrose. The suspensions were immediately filtered through Whatman GF/C filters, washed twice with sucrose buffer and the filters were dried. Radioactivity was measured by liquid scintillation counting in Liquifluor.

Materials. Bovine serum albumin, amino acids, ouabain, nucleotides and all $p$-nitrophenyl substrates were from Sigma; Triton X-100 was from Rohm and Haas; sugars were from either U.S. Biochemical Corp. or Sigma. ${ }^{14} \mathrm{C}$-Labelled sugars (50 to $400 \mathrm{mCi} \mathrm{mol}^{-1}$, uniformly labelled) and Liquifluor were obtained from New England Nuclear. All other chemicals were reagent grade products.

\section{RESULTS}

\section{Stimulation of glycosidase secretion by adding sugars to starvation buffer}

When vegetative amoebae of $D$. discoideum are harvested from growth medium and resuspended in a starvation buffer, they become aggregation-competent within $12 \mathrm{~h}$ (Gerisch, 1968). After the cells were suspended in starvation buffer, $\beta$ - $N$-acetylglucosaminidase activity appeared in the buffer (Fig. 1a). The activity in the buffer normally increased for about 2 to $4 \mathrm{~h}$ before levelling off at a value which corresponded to 20 to $30 \%$ of the total cellular activity. Similar results were obtained for $\alpha$-mannosidase, an acid protease (Rossomando et al., 1978) and acid phosphatase activity. The addition of sodium azide to the starvation buffer at the same time as the cells blocked the release of these activities, suggesting that this release was the result of an energy-dependent secretory process. The addition of $0.1 \mathrm{M}$-galactose or $\alpha$-methyl-D-glucoside to the starvation buffer at the same time as the cells resulted in the release of approximately $90 \%$ of the total cellular glucosaminidase activity in only 4 to $5 \mathrm{~h}$ (Fig. $1 \mathrm{a}$ ). Even after $10 \mathrm{~h}$ of starvation, the control cells (no sugar added) did not secrete more than 20 to $30 \%$ of the total cellular activity. Similar results were obtained for $\alpha$-mannosidase and acid phosphatase activities (not shown) and in each case the stimulation of secretion by the sugars was blocked by sodium azide. As the activity outside the cells increased, the activity remaining within the cells declined to a similar extent (Fig. $1 b$ ), suggesting that neither the added sugar nor secretion itself affected the synthesis of glucosaminidase during the first $10 \mathrm{~h}$ of starvation in suspension.

Various saccharides were examined for their effects on glycosidase secretion (Table 1). The results indicated that a variety of sugars, ranging in size from mono- to tetrasaccharides, could stimulate glycosidase secretion. Sugar alcohols were also effective and with each sugar the secretion of both $\beta$ - $N$-acetylglucosaminidase and $\alpha$-mannosidase activity was stimulated. While none of the sugars tested inhibited secretion to below the control level, 


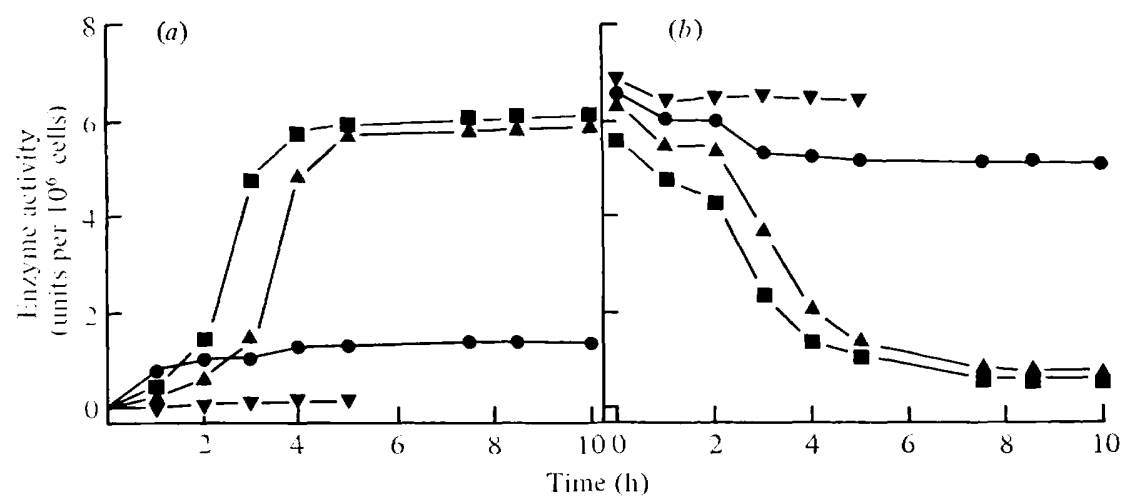

Fig. 1. Stimulation of $\beta$ - $N$-acetylglucosaminidase release by sugars. Cells were suspended in starvation buffer alone (O) or in starvation buffer containing $0.1 \mathrm{M}$-galactose ( $\boldsymbol{\sigma}), 0 \cdot 1 \mathrm{M}-\alpha$-methylD-glucoside $(\boldsymbol{\Delta})$ or $10 \mathrm{mM}$-sodium azide $(\boldsymbol{\nabla})$. At the times indicated, samples of the suspensions were assayed for secreted $(a)$ and cellular $(b)$ glucosaminidase activity as described in Methods.

Table 1. Effect of sugars on glycosidase secretion

Addition*
None
Glucose
Galactose
Mannose
Fucose
L-Fucose
o-Methylglucoside
Maltose
Sucrose
N-Acetylglucosamine
Raffinose
Stachyose
Sedoheptulosan
Cellobiose
Lactose
Melibiose
Galactitol
2-Deoxyglucose
Glycerol
Mannitol
Inositol (meso)

\begin{tabular}{lc}
\multicolumn{1}{c}{ Structure } & Effect \\
& - \\
& ++ \\
& + \\
& ++ \\
& ++ \\
& ++ \\
Glc $\alpha 1 \rightarrow 4$ Glc & + \\
Glc $\alpha 1 \rightarrow 2$ Fru & ++ \\
Gal $\alpha 1 \rightarrow 6$ Glc $\alpha 1 \rightarrow 2$ Fru & ++ \\
Gal $\alpha 1 \rightarrow 6$ Gal $\alpha 1 \rightarrow 6$ Glc $\alpha 1 \rightarrow 2$ Fru & ++ \\
Glc $\beta 1 \rightarrow 4$ Glc & ++ \\
Gal $\beta 1 \rightarrow 4$ Glc & ++ \\
Gal $\beta 1 \rightarrow 6$ Glc & ++ \\
& ++ \\
& ++ \\
& ++ \\
& + \\
& ++
\end{tabular}

* Sugars were added to starvation buffer at a concentration of $0 \cdot 1 \mathrm{M}$. All sugars are the D-isomers unless otherwise stated.

$\dagger++$, Secretion of at least $90 \%$ of the total cellular activity; - , same amount of secretion as the control (no addition); + , greater secretion than the control, but less than $90 \%$.

the metabolizable sugars glucose, maltose and mannose were clearly the least effective in stimulating glycosidase secretion above the control level (Table 1). The term 'metabolizable' refers only to the fact that the sugar enhances vegetative growth when it is the sole sugar added to HL-5 medium (Rickenberg et al., 1975).

With most sugars there was a 1 to $2 \mathrm{~h}$ lag period before the effect of the added sugar became evident. Thus, after $1 \mathrm{~h}$ of starvation, the level of secreted activity was the same regardless of whether any sugar was present. However, when the cells were harvested after $1 \mathrm{~h}$ of incubation with sugar and resuspended in starvation buffer alone, cells which had been exposed to sugar secreted more activity than the control cells (Fig. 2). This result suggested that under these conditions the interaction of the sugar with the cell was not the 


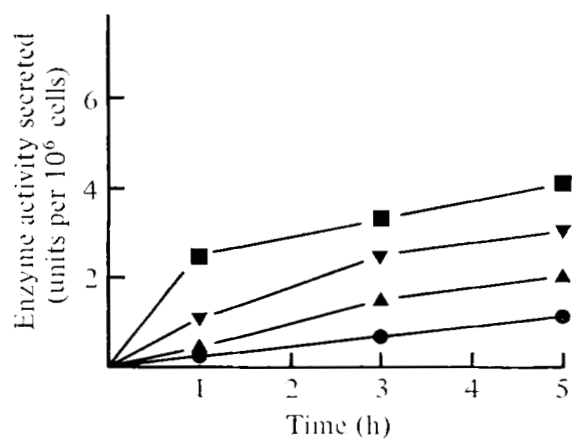

Fig. 2. Effect of preincubation with sugars on $\beta$ - $N$-acetylglucosaminidase secretion. Cells were

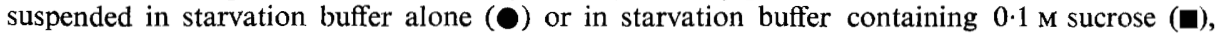
galactose $(\boldsymbol{\nabla})$ or $\alpha$-methylglucoside $(\boldsymbol{\Delta})$ and incubated at $22{ }^{\circ} \mathrm{C}$ on a shaker for $1 \mathrm{~h}$. The cells were then harvested and immediately resuspended in starvation buffer alone (time 0 ). At the times indicated, samples of the suspensions were assayed for secreted glucosaminidase activity.
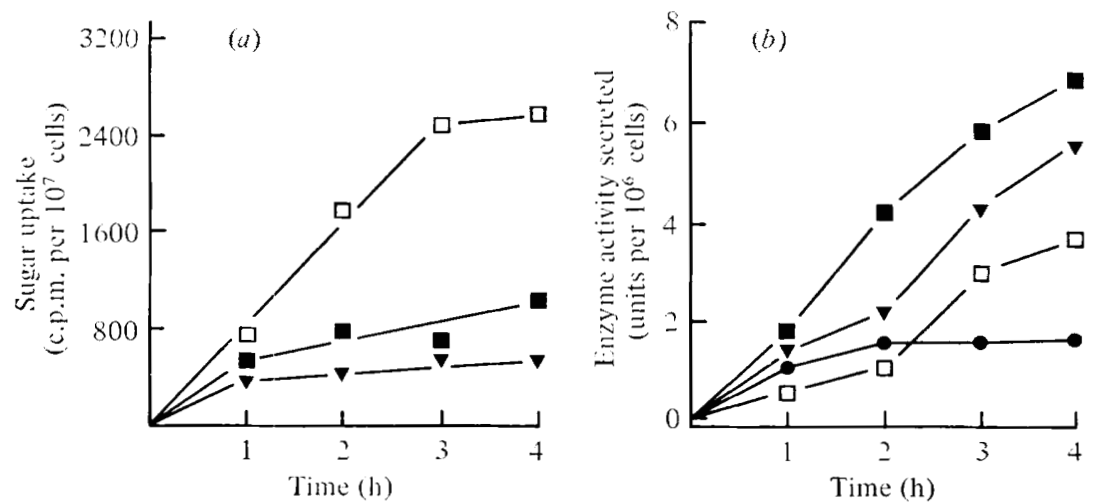

Fig. 3. (a) Rate of sugar uptake in starvation buffer. Cells were suspended in starvation buffer containing $\left[{ }^{14} \mathrm{C}\right]$ mannose $(\square),\left[{ }^{14} \mathrm{C}\right]$ sucrose $(\square)$ or $\left[{ }^{14} \mathrm{C}\right]$ galactose $(\boldsymbol{\nabla})\left(0 \cdot 1 \mathrm{M} ; 10 \mathrm{mCi} \mathrm{mol}^{-1}\right.$; 19180 c.p.m. $=1 \mu \mathrm{mol}$ ) and sugar uptake was measured as described in Methods. (b) Rate of $\beta-N$-acetylglucosaminidase secretion for the same suspensions, as well as for a control without sugar (O).

rate-limiting step in the process by which sugars stimulated secretion. It did appear, however, that continuous exposure to the sugar was necessary to obtain the maximum level of secretion since cells exposed for only $1 \mathrm{~h}$ (Fig. 2) secreted less activity than those which were continuously exposed to sugar (Fig. $1 a$ ).

Of all the sugars tested, sucrose (a non-metabolizable sugar) caused the most rapid stimulation of secretion and was therefore used for most of the subsequent studies. Among the compounds which had no effect on secretion were $0 \cdot 1 \mathrm{M}-\mathrm{NaCl}, 0 \cdot 1 \mathrm{M}$-thymidine, $10 \mathrm{~mm}$ histidine, $4 \mathrm{mM}$-ATP, $2 \mathrm{~mm}-\mathrm{CaCl}_{2}, 1 \mathrm{~mm}$-AMP, $1 \mathrm{~mm}$-pyridoxal phosphate, $1 \mathrm{~mm}$-ouabain and 0.1 mM-cyclic AMP. The observation that different saccharides varied in their ability to stimulate glycosidase secretion and the fact that various salts, amino acids and nucleotides were not stimulatory suggested that the cells were responding to the presence of the sugar and not to a simple osmotic effect.

The rate of sugar uptake by the cells was also examined (Fig. 3). Non-metabolizable sugars were taken up poorly by the cells although they readily stimulated glycosidase secretion, suggesting that there was no correlation between sugar uptake and glycosidase secretion. 


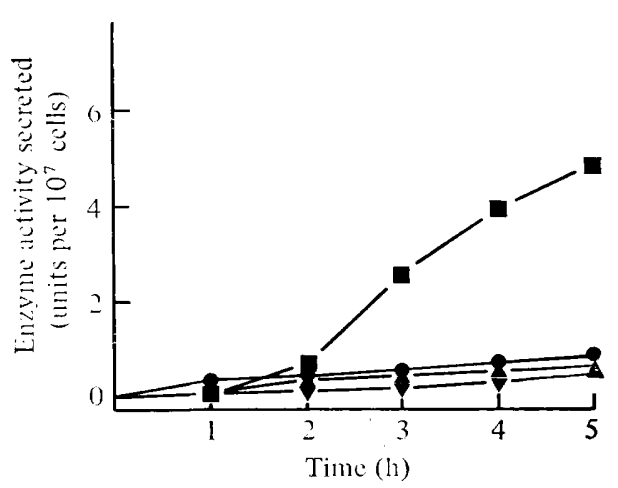

Fig. 4

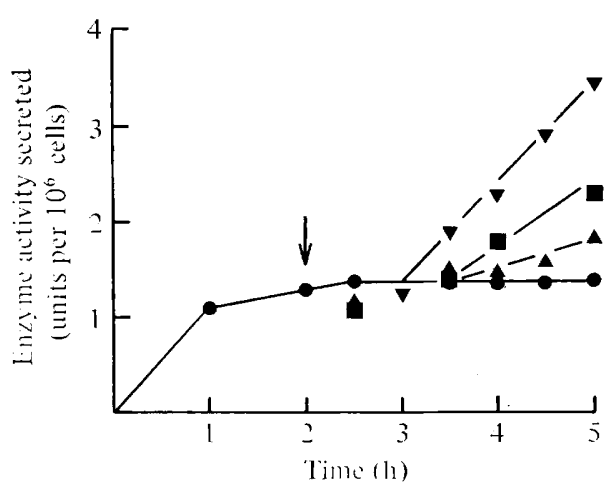

Fig. 5

Fig. 4. $\beta$ - $N$-Acetylglucosaminidase release in the presence of growth medium components. Cells were suspended at $1 \times 10^{7}$ cells $\mathrm{ml}^{-1}$ in starvation buffer containing proteose peptone $\left(15 \mathrm{mg} \mathrm{ml}^{-1}\right)$, yeast extract $\left(7.5 \mathrm{mg} \mathrm{ml}^{-1}\right)$ and either no sugar $(\mathbf{O}), 0.1 \mathrm{M}$-glucose $(\boldsymbol{\nabla}), 0.1 \mathrm{M}$-maltose $(\mathbf{\Delta})$ or $0 \cdot 1 \mathrm{M}$-sucrose ( $\mathbf{D})$ and incubated at $22{ }^{\circ} \mathrm{C}$ on a shaker. At the times indicated, samples of the suspensions were assayed for secreted glucosaminidase activity.

Fig. 5. Effect of sucrose concentration on the rate of $\beta$-N-acetylglucosaminidase secretion. Cells were suspended in starvation buffer at $1 \times 10^{7}$ cells $\mathrm{ml}^{-1}$. After $2 \mathrm{~h}$ (arrowed) portions of the suspension were dispensed in separate flasks containing $0(\boldsymbol{O}), 2 \mathrm{~mm}(\boldsymbol{\Delta}), 4 \mathrm{~mm}(\boldsymbol{\nabla})$ or $8 \mathrm{~mm}(\boldsymbol{\nabla})$ sucrose and incubated at $22{ }^{\circ} \mathrm{C}$ on a shaker. At the times indicated, samples of the suspensions were assayed for secreted glucosaminidase activity.

\section{Specific stimulation of secretion of lysosomal enzyme activity}

Since $\beta$ - $N$-acetylglucosaminidase, $\alpha$-mannosidase and acid phosphatase activities are predominantly associated with lysosomes (Weiner \& Ashworth, 1970; Ashworth \& Quance, 1972 ), it seemed possible that the sugars were specifically stimulating the release of lysosomal enzymes. In support of this, we found that neither alkaline phosphatase nor 5 -nucleotidase, two enzymic activities which have been used as cell membrane marker enzymes in D. discoideum (Gilkes \& Weeks, 1977), was released in starvation buffer in the presence or absence of any sugar. In addition, we found that a non-metabolizable sugar (e.g. $0 \cdot 1 \mathrm{M}$ sucrose) did not affect the kinetics of release of either total protein or of cyclic AMP phosphodiesterase activity. These results are consistent with the idea that the sugars cause the specific stimulation of lysosomal enzyme secretion rather than a general release of cellular proteins through cell lysis or some other non-specific process.

\section{Stimulation of secretion in growth medium}

The ability of sugars to stimulate glycosidase secretion in the presence of other nutrients was also examined (Fig. 4). Cells suspended in phosphate buffer containing yeast extract and proteose peptone secreted little glucosaminidase activity. The amount secreted was less than that secreted in starvation buffer alone (Fig. 1), suggesting that components in either the yeast extract or proteose peptone inhibited glycosidase secretion. While the addition of a metabolizable sugar such as glucose or maltose to the proteose peptone/yeast extract medium had no effect on secretion (Fig. 4), the addition of sucrose stimulated secretion, indicating that even in the presence of other nutrients the cells could still respond to the presence of a non-metabolizable sugar. It should be noted, however, that the amount secreted under these conditions was much less than that observed with sucrose in starvation buffer alone and that there was a $2 \mathrm{~h}$ lag period under these conditions, suggesting that the sucrose could not completely overcome the inhibition caused by the nutrients. 


\section{Effect of sugar and cell concentration on secretion}

The results presented in Fig. 5 demonstrate the effect of sucrose concentration on glucosaminidase secretion in the starvation buffer. For this experiment, the cells were suspended in starvation buffer alone for $2 \mathrm{~h}$, to allow the amount of secreted activity to level off, before addition of sucrose. The concentration of sucrose affected both the length of the lag period and the rate of glucosaminidase secretion. Similar results were obtained for mannosidase secretion, although doubling the sucrose concentration did not double the rate of secretion of this activity. In similar experiments, it was found that varying galactose, mannose and maltose concentrations over a suitable range could also affect both the rate of secretion and the length of the lag period before stimulation was evident. The nonmetabolizable sugars sucrose and galactose increased the secretion rate in the concentration range of 1 to $10 \mathrm{~mm}$ and 10 to $50 \mathrm{~mm}$, respectively, while the metabolizable sugars maltose and mannose required concentrations of greater than $50 \mathrm{~mm}$ to stimulate the rate of secretion, and glucose was not stimulatory even at $150 \mathrm{~mm}$.

The effect of cell density on the amount of glycosidase activity secreted was also studied. Cells suspended in starvation buffer at concentrations ranging from $1 \times 10^{6}$ to $2 \times 10^{7}$ cells $\mathrm{ml}^{-1}$ secreted the same amount of activity per cell (20 to $30 \%$ of the total activity present in cells) and at the same rate. The addition of $0.1 \mathrm{M}$ non-metabolizable sugar to the starvation buffer stimulated both the rate and extent ( $90 \%$ of total) of glycosidase secretion regardless of the cell density, suggesting that secretion was not the result of cell contact.

\section{DISCUSSION}

Dictyostelium discoideum amoebae release glycosidases when the cells reach stationary phase in growth medium (Every \& Ashworth, 1973) or when the cells are suspended in a starvation buffer (Crean \& Rossomando, 1977). The results presented here show that non-metabolizable sugars can stimulate this azide-sensitive release both in nutrient medium and in starvation buffer, and that some metabolizable sugars can stimulate this process in starvation buffer. The sugars appear to stimulate a general release of lysosomal enzymes since the secretion of acid phosphatase and of an acid protease (unpublished results) are also stimulated while no stimulation of total protein or cyclic AMP phosphodiesterase release is evident.

There appears to be some specificity in the sugar stimulation of secretion since specific sugars can enhance secretion over distinct concentration ranges. For example, galactose and glucose differ from one another only by their 4-hydroxyl groups, yet this structural change results in a greater than 15-fold difference in the concentrations at which they can stimulate secretion. This concentration dependence and the inability of various salts, amino acids or nucleotides to stimulate secretion strongly suggest that the effects of adding sugars are not non-specific.

The ability of a sugar to be taken up and retained by cells in starvation buffer appears to correlate well with the ability of the sugar to enhance growth in HL-5 medium. Those sugars which do not promote vegetative growth (non-metabolizable sugars) are taken up poorly by the cells. It is not yet known whether this poor uptake reflects a transport problem or an inability to metabolize the sugars once they enter the cell. Thus it is not known whether a sugar must enter the cell to stimulate secretion. However, comparison of the kinetics of sugar intake with that of glycosidase secretion does not suggest that secretion is a direct consequence of pinocytosis of the sugars. The possibility that the $D$. discoideum cell surface contains sugar receptors through which this stimulation is mediated still exists. Thus, a number of questions regarding the molecular basis for sugar stimulation of glycosidase secretion remain for further study.

It has previously been proposed that the secretion of glycosidases and of an acid pro- 
tease by $D$. discoideum may be developmentally significant (Ashworth \& Quance, 1972; Crean \& Rossomando, 1977; Rossomando et al., 1978). The results of this study, in combination with work reported from other laboratories, raise a number of points regarding this proposition. Rahmsdorf et al. (1976) have shown that $D$. discoideum amoebae suspended in starvation buffer with a metabolizable sugar do not synthesize a number of components which serve as markers for early stages of development in this organism. We have observed that metabolizable sugars do not block the secretion of glycosidases in starvation buffer. In fact, some metabolizable sugars can enhance secretion. Thus, if glycosidase secretion (or, more generally, lysosomal enzyme secretion) is considered to be a developmental event, it must be a very early event since it occurs immediately after removal of nutrients and can occur in the absence of other early development markers such as formation of contact sites 'A' and of cyclic AMP-binding sites. Rickenberg et al. (1975) have examined the effects of preincubation for 8 to $10 \mathrm{~h}$ with $0 \cdot 1 \mathrm{M}-\alpha$-methylglucoside and other sugars on $D$. discoideum aggregation and morphogenesis. We have found that over $90 \%$ of the cellular glucosaminidase and mannosidase activities are usually secreted under these conditions and that little activity remains with the cells. Rickenberg et al. (1975) found that these preincubated cells developed normally when subsequently deposited on membrane filters in the absence of sugars although preincubation with some sugars retarded subsequent development to some extent. Thus, enhancing the level of extracellular glycosidases during the preincubation period does not increase the rate of either aggregation or morphogenesis. However, if neither glycosidase secretion nor the action of the secreted enzymes on the cell surface represents a rate-limiting step in early $D$. discoideum development, one would not expect an increase in these processes to increase the rate of aggregation or morphogenesis. Thus, cells suspended in starvation buffer containing a metabolizable sugar may be blocked at a stage of development which is subsequent to the stage of glycosidase secretion, but preceding the stages marked by the formation of cyclic AMP-binding sites and contact ' $A$ ' sites.

The preliminary observation that components of yeast extract or proteose peptone may be capable of blocking glycosidase secretion suggests that secretion could be an initial response to the exhaustion of a particular nutrient other than sugars. The work of Marin (1976) has suggested that the absence of particular amino acids may serve as a signal for the onset of development. Since a completely defined medium is now available for $D$. discoideum (Franke \& Kessin, 1977), it should be possible to determine whether particular nutrients can regulate the onset of secretion and whether this control is correlated with control over the onset of development (Marin, 1976, 1977).

In recent studies, de Chastellier \& Ryter (1977) have examined the digestive system of $D$. discoideum during the first $5 \mathrm{~h}$ of starvation. Their electron microscopic observations suggest that the entire digestive system is transformed into an autophagic apparatus during this period, and their results further suggest that the secretion of hydrolase activities may be a normal part of this process. Thus, our results are consistent with the possibility that the addition of sugar to the starvation buffer can stimulate this transformation process. In addition, a preliminary electron microscopic examination of cells starved in a buffer containing sugar has revealed that the vacuolar system of these cells is markedly different from that of cells starving in buffer alone (unpublished observations).

The results of this study suggest that further examination of the effects of sugars on starving $D$. discoideum amoebae will provide useful information regarding the role of the digestive system in $D$. discoideum morphogenesis. In addition, the extracellular medium obtained from cells which have been starved in the presence of a non-metabolizable sugar for 3 to $4 \mathrm{~h}$ should provide a rich source for the isolation of hydrolytic enzymes which can then be examined for their effects on $D$. discoideum cell surface components and on the complex process of morphogenesis itself. 
The authors are grateful to Richard Gaines, Peter Lagerstedt and Susan Scott for their excellent technical assistance. This work was supported by N.I.H. grants DEO 3715 and 5 T22 DEO 0202.

\section{REFERENCES}

Ashworth, J. M. \& Quance, J. (1972). Enzyme synthesis in myxamoebae of the cellular slime mould Dictyostelium discoideum during growth in axenic culture. Biochemical Journal 126, 601608.

Crean, E. V. \& Rossomando, E. F. (1977). Developmental changes in membrane-bound enzymes of Dictyostelium discoideum detected by concanavalin A-Sepharose affinity chromatography. Biochemical and Biophysical Research Communications 75, 488-495.

de Chastellier, C. \& Ryter, A. (1977). Changes of the cell surface and of the digestive apparatus of Dictyostelium discoideum during the starvation period triggering aggregation. Journal of Cell Biology 75, 218-236.

Every, A. \& Ashworth, J. M. (1973). Purification and properties of extracellular glycosidases of the cellular slime mould Dictyostelium discoideum. Biochemical Journal 133, 33-47.

Franke, J. \& Kessin, R. (1977). A defined minimal medium for axenic strains of Dictyostelium discoideum. Proceedings of the National Academy of Sciences of the United States of America 74, 2157-2161.

GERISCH, G. (1968). Cell aggregation and differentiation in Dictyostelium. Current Topics in Developmental Biology 3, 157-197.

GiLkes, N. R. \& WeEKs, G. (1977). The purification and characterization of Dictyostelium discoideum plasma membranes. Biochimica et biophysica acta 464, 142-156.

Loomis, W. F., JR (1969). Acetylglucosaminidase, an early enzyme in the development of Dictyostelium discoideum. Journal of Bacteriology 97, $1149-1154$

Looms, W. F. (1975). Dictyostelium discoideum: $A$ Developmental System. New York: Academic Press.

Lowry, O. H., Rosebrough, N. J., Farr, A. L. \& Randall, R. J. (1951). Protein measurement with the Folin phenol reagent. Journal of Biological Chemistry 193, 265-275.

MARIN, F. T. (1976). Regulation of development in Dictyostelium discoideum: I. Initiation of the growth to development transition by amino acid starvation. Developmental Biology 48, 110-117.

MARIN, F. (1977). Regulation of development in Dictyostelium discoideum: II. Regulation of early cell differentiation by amino acid starvation and intercellular interaction. Developmental Biology 60, 389-395.

Rahmsdorf, H. J., Cailla, H. L., Spitz, E., Moran, M. J. \& RickenberG, H. V. (1976). Effects of sugars on early biochemical events in development of Dictyostelium discoideum. Proceedings of the National Academy of Sciences of the United States of America 73, 3183-3187.

RickenberG, H. V., Rahmsdorf, H. J., Campbell, A., North, M. J., KWasniak, J. \& Ashworth, J. M. (1975). Inhibition of development in Dictyostelium discoideum by sugars. Journal of Bacteriology 124, 212-219.

Rossomando, E. F., Steffex, A. J., Mujwid, D. K. \& AleXANDER, S. (1974). Scanning electron microscopic observations on cell surface changes during aggregation of Dictyostelium discoideum. Experimental Cell Research 85, 73-78.

Rossomando, E. F., Maldonado, B., Crean, E. V. \& Kollar, E. J. (1978). Protease secretion during onset of development in Dictyostelium discoideum. Journal of Cell Science 30, 305-318.

WeINer, E. \& Ashworth, J. M. (1970). Isolation and characterization of lysosomal particles from myxamoebae of the cellular slime mould Dictyostelium discoideum. Biochemical Journal 118, 505-512.

White, G. J. \& Sussman, M. (1961). Metabolism of major cell constituents during slime mould morphogenesis. Biochimica et biophysica acta $53,285-293$. 